https://helda.helsinki.fi

\title{
Asymmetries of Knowledge and Epistemic Change in Social Gaming Interaction
}

\section{Piirainen-Marsh, Arja}

2014-11-14

Piirainen-Marsh , A \& Tainio , L 2014 , ' Asymmetries of Knowledge and Epistemic Change in Social Gaming Interaction ' , Modern Language Journal , vol. 98 , no. 4 , pp. 1022-1038 . https://doi.org/10.1111/m http://hdl.handle.net/10138/230994

https://doi.org/10.1111/modl.12153

acceptedVersion

Downloaded from Helda, University of Helsinki institutional repository.

This is an electronic reprint of the original article.

This reprint may differ from the original in pagination and typographic detail.

Please cite the original version. 
Asymmetries of Knowledge and Epistemic Change in Social Gaming Interaction

Piirainen-Marsh, A. \& Tainio, L. 14 marraskuuta 2014 julkaisussa : Modern Language

Journal. 98, 4, s. 1022-1038

\title{
ASYMMETRIES OF KNOWLEDGE AND EPISTEMIC CHANGE IN SOCIAL GAMING INTERACTION
}

\begin{abstract}
While a growing number of studies investigates the role of knowledge and interactional management of knowledge asymmetries in conversation analysis, the epistemic organization of multilingual and second language interactions is still largely unexplored.

This article addresses this issue by investigating how knowledge asymmetries and changing positions with regard to knowledge impact social interaction in multilingual gaming activities. Drawing on a collection of video recordings of naturally occurring social gaming sessions collected over a two year period and involving the same two participants, we examine how the participants orient to knowledge and deal with knowledge asymmetries while solving game related problems and tasks. In addition to detailed analysis of local aspects of epistemic organization, we examine how participant's epistemic positions change over time. Findings show that epistemic changes impact the social organization of the gaming activities and constitute the situation as a learning event.
\end{abstract}


Keywords: epistemic organization, epistemic asymmetry and change, interaction, social gaming

\section{Introduction}

This article investigates how knowledge asymmetries and changing positions with regard to knowledge impact the organization of social gaming interaction and have consequences on the participation, identities, and relations of the participants. The data is drawn from a series of videorecorded gaming interactions, which involve multilingual language use. The analysis focuses on the detailed ways in which the participants orient to knowledge, while engaging with specific game tasks or situations: what kind of knowledge is needed and treated as relevant to solve a problem or task; how this knowledge is displayed linguistically and through other interactional resources; how it is made relevant locally, and how the participants orient to and deal with asymmetries of knowledge. In addition to detailed analysis of knowledge management in the context of local game tasks and situations, we examine how the participants' epistemic positions change over time by comparing data from temporally spread social gaming interactions involving the same two participants. The analysis shows that epistemic asymmetries and change constitute a joint, multilingual video gaming activity as a learning event. We suggest that epistemic changes, as displayed in the participants' interactional positionings to linguistic and game knowledge and their orientations to the distribution of this knowledge, are constitutive of trajectories of learning (cf. Melander \& Sahlström, 2011). More specifically, they offer insight into the kinds of interactional competencies involved 
in learning to read meanings and jointly navigate continually changing game situations in the semiotically rich setting.

The analysis draws on the growing body of research applying conversation analysis to investigate the learning and development of interactional competences in multilingual and second language interaction (see e.g. Hall, Hellermann \& Pekarek Doehler, 2011; Pallotti \& Wagner, 2011). A large number of studies describe how participants in interaction accomplish learning as practical activity by deploying generic interactional practices of turn-taking, repair and the like, in both classroom and everyday contexts (e.g. Carroll, 2006; Hellermann, 2008; Kasper, 2004; Markee, 1994, 2000; Markee \& Seo, 2009; Mondada \& Pekarek Doehler, 2004; Mori, 2004 ). While the main interest in these studies is in documenting participants' competencies "in action", another group of studies traces the development of interactional competence by comparing the same (group of) learners' participation in temporally spread interactions (e.g. Brouwer \& Wagner, 2004; Cekaite, 2007; Hellermann, 2008; 2011; Ngyen, 2011, 2012). This study adds to earlier work in this field by investigating the kinds of competencies that underlie participation in social gaming activities and documenting changes in such competences. With interactional competences, we mean the context-specific types of knowledge and skills that enable participants to make sense of and navigate social situations (see e.g. Hall \& Pekarek Doehler, 2011; Kasper \& Wagner, 2011). Such competences are manifested in the mundane practices through which interaction is organized (e.g. repair, turn-taking) as well in the "embodied doing, thinking and knowing" made public in social activities (Sahlström, 2011, pp. 47, 48). 
In conversation analysis the role of knowledge in interaction has recently emerged as a rich field of study which sheds new light on the ways in which actions are formed and interactively organised in a variety of settings (see e.g. Drew, 1991; Heritage, 2012a, 2012b; Stivers, Mondada \& Steensig, 2011). Yet so far only a few studies have explored the epistemic organization of multilingual and second language interactions. Focusing on interaction in multilingual classrooms, Koole (2010, 2012a, 2012b) examines one-to-one interactions between a teacher and a student asking for help with a mathematics problem. He describes how the problem is addressed and managed through an interactionally organized explanation activity, which provides for an epistemic organization where the teacher rather than the student has primary access to and authority over the problem. In this article, we focus on the epistemic organization of social gaming interaction as a multilingual activity setting which creates specific kinds of affordances for interaction. We describe how participants orient to their relative distribution of knowledge and how they manage their positions with regard to knowledge drawing on multiple linguistic, interactional and embodied resources.

In the sections to follow, we analyse co-located gaming activities in which two participants are playing two games from the fantasy role play series Final Fantasy. In both games the player operates a few playable characters, leading them through a series of challenges and action-packed battle scenes in order to advance in the game. In the gaming interactions in focus, the participants routinely orient to the relevance of who knows what as they navigate the game and talk about it during play. Knowledge of the game and its features (plot, features of the game world, gameplay options etc.) is central 
to solving problems and advancing in-game tasks or projects. The players draw on such knowledge when managing the game, but also topicalise it, comment on it and display their positions toward it in the course of play, thereby negotiating their epistemic positions and stances in interaction (Heritage, 2012a, 2012b; Stivers, Mondada \& Steensig, 2011). Since the language of the game (English) is a second language to the participants whose first language is Finnish, the ability to navigate the game and make sense of its trajectory rests on the competencies involved in reading and interpreting textual information in English as well as visual images displayed on the screen, and the ability to respond to such information in a way that is relevant to the situation or task of the moment. Claimed or displayed epistemic positions thus intertwine with the complex inferential and sequential work through which participants interact with the game and each other in the course of play. The analysis aims to elucidate how epistemic positions are dynamically negotiated in gaming activities, in other words how they are "displayed, claimed, attributed, revised" and also "newly acquired" (Mondada, 2011 p. 27) in the moment-by-moment actions and evolving participation frameworks of the interactional moments engendered by specific game situations and tasks. Through detailed analysis and comparison of interactions involving two players at the age of 11 and a later set of recordings from the same participants c. two years later (age 13), we show how the two participants' epistemic positions in respect to the game and the multilingual character of the situation change over time and have consequences for their participation, roles and relations.

\section{Recreational gaming as a context for learning}


Research on games, gaming literacies, game-play activities, and their potential for enhancing learning has flourished in recent years (see e.g. Cornillie, Thorne \& Desmet, 2012; Salen, 2008). Empirical research across disciplines suggests that playing computer and video games has an impact on both the cognitive and social aspects of development. Experimental studies in psychology and psycholinguistics have shown that extended experience of playing computer games shapes attention processes and develops certain skills (e.g. Bialystok, 2006; Green \& Bavelier, 2003). Studies investigating players' social interaction during online or console-operated gaming have observed that gameplaying offers new opportunities for participation and collaborative activity. Studies of co-located gaming, for example, have shown how joint play may involve expert-novice relations and enable peer tutoring through which novice players learn about the expert vocabulary as well as practical know-how of games (Hung, 2011; Schott \& Kambouri, 2006; Sjöblom, 2011). Studies of multiplayer online games describe how players are socialised to the practices of both virtual and real life communities (Ducheneaut, More \& Nickel, 2006; Steinkuehler, 2006, 2008). Recently increasing attention has been paid to gaming as a context of cultural and discursive activity (see e.g. Gee, 2007; Thorne 2008). A growing number of studies investigating diverse social gaming encounters describe the detailed verbal practices and embodied resources through which players respond to continually changing game situations (e.g. through response cries and metacommentary, see Aarsand \& Aronsson, 2009), move between virtual and real spaces (Keating \& Sunakawa, 2010, 2011), and organise their participation in "in-game" and "out-of-game" talk (Mondada, 2012, 2013). Findings document how players build interactional sequences involving a range of verbal practices, including requests, directives, 
assessments, complaints, cheating and blaming (Hung 2009; Newon 2011; Sjöblom 2011).

Gaming interaction can be characterised as an affinity space (Gee, 2003) and activity setting which affords opportunities for multilingual or L2 language use. A number of studies show how commercial Massively Multiplayer Online Games (MMOs) have created new opportunities for interacting in a foreign language (Thorne, 2008, 2010; Thorne, Black \& Sykes, 2009). Hung (2011) describes how a group of adolescent immigrants from China make sense of fighting games with limited linguistic expertise in the language of the game and how opportunities for learning are created through situated language use and actions during gameplay, which include explicit instruction as well as teasing and cheating. [author 1] and [author 2] (2009a, 2009b) and [author 1] (2010, 2011, 2012) examine the practices through which co-present players draw from locally available L2 language resources such as on-screen texts, voiced dialogue, and the utterances of other participants in constructing play as social activity in the context of a fantasy role play game. The findings of these studies show how games provide specific kinds of techniques and semiotic resources for interacting in a second language. Detailed analysis of the verbal and embodied resources used reveals how participants make use of these techniques in solving game-related problems and negotiating social organisation among multilingual participants. However, the ways in which language resources interact with the competencies involved in managing game-related tasks in the continually changing environment are still largely unexplored. Another limitation of earlier work is that so far research has focused on specific occasions of play. Future research needs to address how the discursive competencies involved in gaming in multilingual contexts 
may develop through recurrent, sustained participation in gaming. This question can be addressed by comparing observations of the same participants' interactions in similar practices over time. Although tracing development involves many challenges, such as identifying units of analysis for comparison and analytically addressing changes in highly context-specific social activities across settings (see Hall \& Pekarek Doehler 2011), multimodal conversation analysis offer a rich methodology for documenting how the participants display their changing interactional competences as they navigate the complex tasks of gaming and organise their social relations in the course of the activity.

In this paper we consider how the knowledge and competencies involved in play evolve both moment-to-moment and change over time through repeated participation in joint co-located gaming. To this end, we draw on two temporally spread data sets involving the same participants to examine what kinds of changes can be observed in the players' orientation to a joint gaming activity, in particular the less experienced player's participation, over a period of two years. Our analysis focuses on the ways in which players deal with various local tasks and problems that arise in the course of play. The design of the game assures a range of tasks to be carried out and problems to be solved in order to proceed in the game. This is one of the characteristics that make the activity of playing both challenging and pleasurable for players. With the analysis of selected excerpts from our data we intend to show how players recognize a problem or task, make relevant specific kinds of knowledge to interactively negotiate the task, and how they collaboratively try to resolve problems drawing on their prior knowledge of the game and game's language, close monitoring of the unfolding situation and interactional practices. 
The game situations and tasks in focus make visible the participants' orientations to knowledge asymmetries and involve displays of understanding or non-understanding that are characteristic of situations involving learning through peer interaction (Sahlström, 2011). The interactional organisations and practices found in these environments provide conditions for developing interactional competence in action, in the course of learning the know-how of the game.

\section{Data and methodology}

The empirical data consist of c. 13 hours of video-recorded interactions where two adolescents (L1 Finnish) are engaged in playing console-operated video games produced in English in a domestic setting. The sessions were recorded with two cameras, one focused on the players and the other on the television screen showing the game. The first set of recordings was made when the players were 11 years old and frequently got together to play Final Fantasy IX, the ninth installment in the popular fantasy role play game series. Altogether 7 gaming sessions were recorded over a two week period. The same players were videorecorded again c. 25 months later at the age of 13. Again 7 sessions were recorded over a period of three weeks. In these data the game of their choice was the tenth installment in the same series, Final Fantasy X. The recordings thus allow comparison of interactions in order to document changes in participation both in the short term and over a time span of c. two years.

The gaming takes place in the home of one of the players. This player (Pete) owns the games and has, at least initially, more experience and expertise in playing these specific games. The boys' background shows some asymmetry also with respect to the 
game language. Both have learned English as a foreign language in Finnish comprehensive school, but prior to the first recordings, Pete had lived in an English speaking country for c. 1 year with his family. The social gaming encounters also involve an inbuilt asymmetry in that only one of the players is in control of the game at a time. In the early recordings the owner of the game (Pete) is the active player almost exclusively, whereas the later recordings show more a balanced pattern of participation where the players take turns in using the controller. All interactions involve frequent verbal, vocal and embodied participation by both players.

As studies of games and gaming interaction have shown, the structures of different games enable and elicit particular opportunities for and stances towards action, interaction and knowing (see e.g. Salen, 2008). The games in the Final Fantasy series involve several playable characters, which the players operate with the help of the controller. The games in focus, Final Fantasy IX and X differ in terms of the plot, gameworld and characters, but also share some features. In both games the player operates the protagonist and other playable characters in the field, leading them through a series of challenges and battles against an evil force. Final Fantasy IX is set in two different worlds, Gaia and Terra. After Terra was destroyed (centuries before the game begins), the Terran people set out to assimilate Gaia, assisted by the villain Kuja. The main protagonist, Zidane Tribal leads a party to battles against the antagonists. Game-play is based on gaining experience points to achieve new levels. The player can also gain new abilities by equipping items that can 'teach' an ability. This enables players to gain ability points. Final Fantasy $\mathrm{X}$ is set in the fictive world of Spira and its plot centers around a group of adventurers: a young male hero called Tidus and a team of crusaders, who go on 
a quest to defeat an evil force known as Sin. In game-play, the characters move through a "Sphere grid". The player gains ability points from battles and by collecting different types of spheres. Final Fantasy X features a new battle system, which influences gameplay. The new system allows the player more time for decision-making (action stops while the players considers options). The player is also able to change characters during battle.

Although they are different games, the two installments require similar kinds of knowledge about the procedures and practices of gaming. Further, the boys' prior experience with the earlier installment can be expected to shape their ability to negotiate gameplay in Final Fantasy $\mathrm{X}$ in the later interactions. A key difference between the games that is relevant to the analysis is the different role of written text in the games. In Final Fantasy IX, the in-game dialogue between the characters is presented as text bubbles and subtitles; in Final Fantasy $\mathrm{X}$ also the voice over dialogue and narrative is available, together with subtitles on the screen. Whereas the later installment enables the players to pick up clues through voiced dialogue as well as through visual cues, the earlier game relies solely on written English, which often causes problems for the 11year-old players.

The data have been transcribed using the conventions of conversation analysis (e.g. Arminen, 2005). To enable detailed analysis of the video data, a multimodal transcript was developed which uses separate lines for representing the participants speech (verbal turn and its translation), their embodied conduct (gaze, body movements, gesture) and physical actions (e.g. actions taken with the control) as well as the game characters' 
speech and actions when relevant to the analysis. An effort has been made to represent as accurately as possible the concurrent actions taking place as the players interact with the game, for instance using the controller to make choices in text menus or moving the playable characters to advance in the game. For clarity, the game characters' spoken turns in Final Fantasy X are indicated by their initials in lower case (e.g. w=Wakka) and the players' turns by their initials in upper case $(\mathrm{P}=\mathrm{Pete}, \mathrm{K}=\mathrm{Kapa})$. Visual information (e.g. texts displayed on the screen) is provided in images and text boxes.

The data are analysed using the micro-analytic tools of conversation analysis, which enable detailed description of the verbal and embodied practices employed. While participation in play involves the same kinds of interactional competences as other types of activity (such as the ability to recognize and use resources for turn-taking, repair and structural organization; Hall \& Pekarek Doehler, 2011; Ngyen, 2012), it is also shaped by the affordances of technology (the game system) and design features which structure interaction and modes of reasoning in specific ways (Arminen, 2005; Cekaite, 2009). In order to analyse the complex multimodal organization of game-playing we draw on recent multimodal research on situated action (Goodwin, 2000, 2007; Goodwin \& Goodwin, 2012) and in particular studies of technology mediated action such as gaming (e.g. Keating \& Sunakawa, 2010, 2011; Mondada, 2012, 2013). Multimodal analysis makes it possible to observe how players interact with the visual images and texts displayed on the screen and use these as resources for organizing action and establishing or maintaining joint attention and understanding.

Before proceeding to the analysis, it is useful to consider how the participants' background and contextual specifics impact the epistemic organization of the situation. In 
the light of contextual features, it is clear that the two participants' relative access to the domain of knowledge of the games, i.e. their epistemic status (Heritage, 2012a) differs, at least initially. This asymmetry arises in part from the participants' background. The game belongs to Pete, who is also the more experienced player. Having spent time in an English speaking country, Pete also has more linguistic expertise. In addition to these bacground features, the epistemic organisation of the interaction is shaped by the gaming situation. In gaming the object of knowledge (the game) is also the object of simultaneous experience (Stivers, Mondada \& Steensig, 2011) for the participants engaged in play. However, their positions are different. While the participants have shared visual access to information on the screen, only one player is in control of the game console and responsible for the actions that advance the game. The choices that he makes and the success or failure of his actions are often immediately visible (e.g. as points displayed on the screen) and open to evaluation by both parties. The analysis focuses on the way that the participants orient to and deal with the asymmetries related to epistemic status and epistemic access in the context of specific game tasks and situations, and demonstrates how the participants' relations are altered and renegotiated through the moment-by-moment expression of epistemic stances (Heritage, 2012a, 2012b).

\section{Epistemic asymmetries and change}

When managing game tasks and solving problems, the players encounter different kinds of epistemic asymmetries related both to the game and its features and the game's language. Through close analysis and comparison of temporally spread verbal 
interactions between the players whilst they engage with specific game situations, it is possible to trace the participants' orientations to these asymmetries and document a player's movements from the less knowing participant to the position of expert player. In the analysis that follows, we trace the development of the more novice player, Kapa, from a learner and beginner to an equal partner in joint gaming. We examine how the participants' relative epistemic status changes in the course of repeated occasions of play over a period of two years.

\section{Managing epistemic asymmetry}

We begin by showing how the participants display their orientation to knowledge asymmetry in the first set of recordings where the participants, then age 11, play Final Fantasy IX. The first three examples demonstrate how the players use the texts offered by the game as a resource for making public their understanding of the game situation for the purposes of solving emerging problems. The treatment of the texts in interaction is intertwined with the practices of recognizing and dealing with an emerging problem. Displays of epistemic asymmetry can be identified in the practices through which the problem is noticed or recognized, such as reading aloud textual elements on the screen and the treatment of these texts in the interaction (e.g. Excerpt 1), asking questions or requesting clarification (e.g. Excerpt 2) and initiating repair (e.g. Excerpt 3).

The first example, which is taken from the very first recordings, shows how the players' asymmetries of knowledge both in relation to know-how about the game and the language of the game are manifested in the course of play. The players are sitting relaxed 
on a sofa, leaning back. Pete is playing, while Kapa $(\mathrm{K})$ follows the scene, with a toy gun in his hand. The game situation is a battle scene involving four playable characters, one of whom is Quina. Quina (a member of the "Qu" tribe) is known in the game for its poor language skills and strange eating habits. The character's trait to eat almost anything turns out to be a valuable skill as the character gains special powers (Blue Magic) by consuming enemies. Here Quina is shown to attack the enemy attempting to eat it. The screen shows rapidly changing texts which provide information about the playable characters' powers in the attack, the points scored in the battle and command menus. For clarity, these are presented in the transcript as text boxes which indicate when a particular text appears on the screen. The player's choices are visible through the cursor movements on the screen.

EXCERPT 1. FFIX: Mustard Bomb.

1 K ${ }^{\circ}$ vähän karun näkönen tuo ${ }^{\circ}$ ${ }^{\circ}$ looks a bit rough ${ }^{\circ}$

$2 \quad \mathrm{P} \quad+\downarrow \operatorname{din} \uparrow \operatorname{din} \downarrow \operatorname{din} \uparrow \operatorname{din} \downarrow \operatorname{din} \uparrow \operatorname{din}($.

$+(($ points to 'attack' on command menu -->)) 


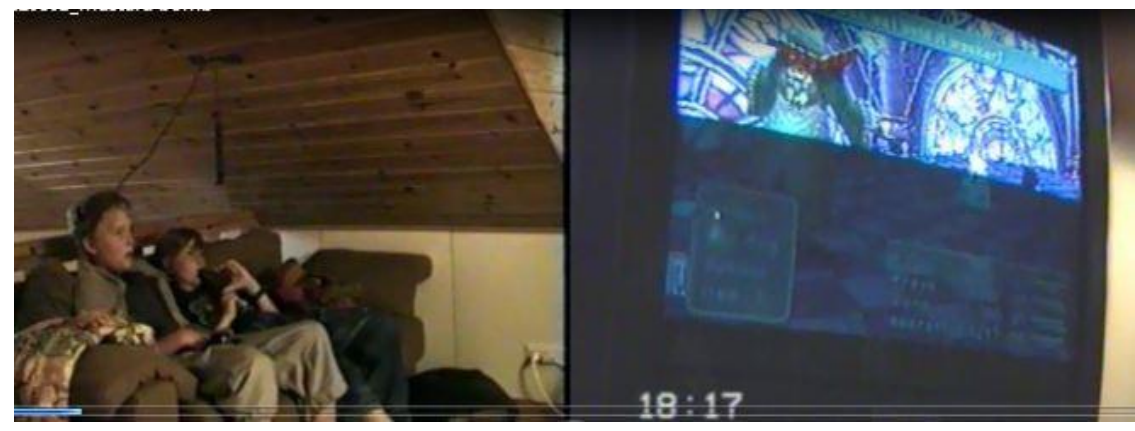

Fig. 1. Quina: I no can eat until weaker.

$3 \rightarrow \mathrm{P} \quad$ [I can't eat until viik:er

Commands:

Attack

[ ((selects attack))

Jump

4 (.) $[((\mathrm{K}$ fires toy gun $))$

$5 \quad \mathrm{~K} \quad<\mathrm{n}[\mathrm{o} \uparrow \mathrm{ih}>]$

$<\operatorname{th}[\mathrm{e} \uparrow \mathrm{re}>$

6 P [kökkö]

[stupid]

((--- > P continues to 'Attack'))

$7 \quad$ (.) ((attack ends)) 
$8 \rightarrow \mathrm{K} \quad$ mikä on <jumppi> (.) mitä sillä tekkee what's $<$ jump $>$ (.) what can you do with it

10 P Mustard Bomb (.) vähän tuo on ${ }^{\circ}$ hullun hyvä Mustard Bomb (.) that is ${ }^{\circ}$ so good ${ }^{\circ}$
$11 \rightarrow \mathrm{K} \quad+($
) +Sina:ppipommi.
+ Musta:rd bomb.
$+(($ points with toy gun, + fires towards the screen $))$

As Quina appears on the screen close up, K quietly comments on its appearance (line 1). Pete is actively engaged in the game: he attempts to attack the enemy (i.e. by eating it) and displays his involvement by vocalizing the sounds related to the fight (line 2). However, at the same time, a text representing Quina's words in ungrammatical English briefly appears on the screen (Fig. 1). The text indicates that eating the enemy is not an option at this point in the game. In line 3 Pete reads the text aloud, but corrects its language to form a grammatical English utterance. With this activity he indexes the newsworthiness of the information and displays his position of epistemic primacy based 
on expert knowledge about the game, including linguistic expertise beyond that of the game character. In addition to being grammatical, his turn is pronounced according to the English phonological system apart from the last word, which is a hybrid form.

At the same time, Pete continues to engage in the battle scene. He selects the command 'attack' from a command menu (lines 2-4) and briefly comments on the events in the battle (line 6) in overlap with Kapa's utterance which seems to accept and appreciate his game play move (line 5). After that Kapa focuses on one of the other commands displayed on the screen ('Jump') and asks Pete about it (line 8). With the information seeking question he displays limited access to knowledge related to features of gameplay and positions himself as a novice player in relation to Pete. He also orients to the bilingual situation by using a hybrid language form: he borrows the English game term but pronounces it according to the Finnish phonological system (e.g. adding the vowel $\mathrm{i}$ in the end of the word). However, Pete does not answer Kapa's inquiry but instead concentrates on the on-going battle. The screen now shows that Quina has acquired a new ability, Mustard Bomb, which makes the character more powerful in the battle. Pete reads the game term aloud and produces a positive assessment (line 10), thereby appreciating the new development. Kapa, who is simultaneously involved with an alternative activity (playing with a toy gun) also attends to the screen and aligns with Pete by translating the name of the acquired ability to Finnish (line 11). This makes evident that also Kapa has relevant knowledge and expertise in English. With his translation Kapa responds to Pete's assessment and creates a moment of shared appreciation, which reduces the epistemic asymmetry and builds affiliation between the participants. 
Epistemic asymmetry is observable also in the next Excerpt (Excerpt 2), which comes from a larger sequence where the players negotiate a difficult task in a scene that is unfamiliar to both of them. The scene is located in "Desert Palace" and involves one playable character who is searching for a way to advance. Texts displayed on the screen give clues about how to proceed. For the participants, however, part of the difficulty lies in the clues themselves: they can be linguistically complex and hence not always easy to understand for second language speakers. An additional challenge is that the activities that the clues suggest should be carried out in a certain order. In the beginning of this Excerpt Kapa reads aloud part of a clue that appears on the screen. The activity of reading aloud marks this text as a visual trouble source (Cekaite, 2009; Greiffenhagen \& Watson, 2009).

EXCERPT 2. FFIX: The path will open.

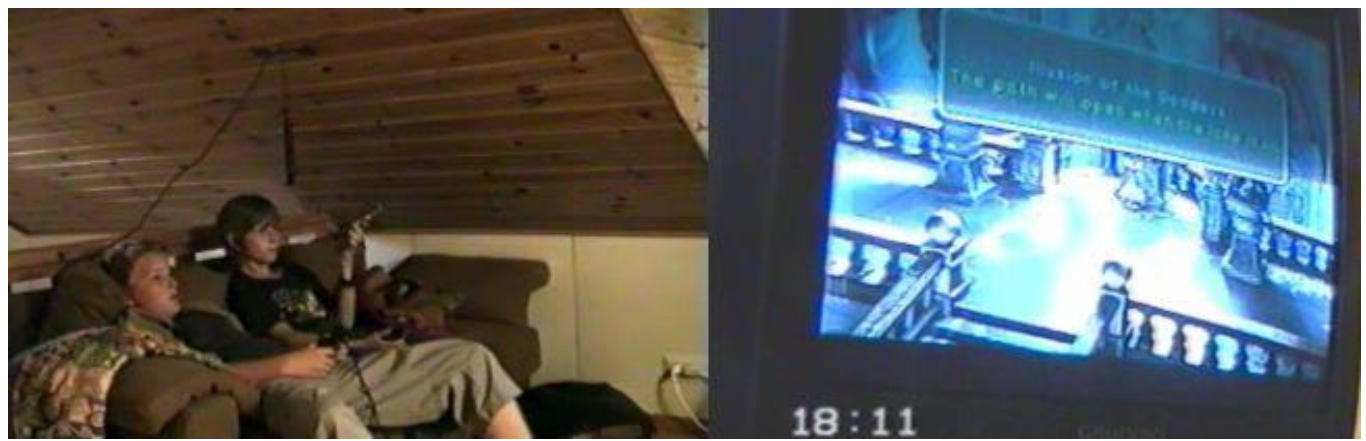

Fig. 2. Illusion of the goddess. The path will open when the lamp is lit. 
$1 \mathrm{~K} \quad[(($ plays with toy gun, turns gaze to screen $))$

$[(($ Pete moves game character close to a figure on staircase $))$

$2 \rightarrow \mathrm{K} \quad$ [the path will open when the lamp is it

$$
\begin{aligned}
& \text { Truth of the devil. } \\
& \text { The bloodstone is } \\
& \text { proof of his power. }
\end{aligned}
$$

3

(3.0) ((character continues searching --- >))

$4 \rightarrow \mathrm{K} \quad$ mitäh in-

what in-

5

(.)

$6 \rightarrow \mathrm{K}$ mitä siinä luki,

what did it say,

7

(.)

The bloodstone is the source of his power.

Each colour holds different powers.

$8 \quad \mathrm{P} \quad$ että $\uparrow$ truu bot- blotstone

that true bot- blotstone 
Throughout the scene Pete is manipulating the playable character by moving him around so as to get him close to spots where new clues might be offered (e.g. in front of doors and next to candle lights). When the first clue appears (Fig. 2), Kapa reads it aloud, although he does not repeat it quite correctly (line 2). After a moment Pete moves the character to a new spot (line 3) which brings out more clues (see text box, line 2). Kapa is unable to follow these and he displays trouble by initiating repair and asking for clarification (lines 4 and 6). He thus orients to Pete's epistemic primacy and treats him as the party with both access to the relevant information and the authority to provide that information. Pete aligns with this position by answering the question: he picks up and reproduces a key term (Bloodstone, line 8) which appears twice in the textual clues (lines 2 and 7), thereby displaying not only his recognition of the term, but also an understanding that knowledge of it is crucial if the player wants to proceed in the game. Bloodstone is a key term in the game: in order to proceed in Desert Palace, the players must deactivate its security system by turning off bloodstones which are scattered around in the palace. However, even if Pete acknowledges and communicates the importance of this term, his actions do not display understanding of what to do. In this excerpt the players' positioning is one of epistemic congruence (Stivers, Mondada \& Steensig, 2011 p. 10): they agree that Pete has both better access and greater epistemic primacy; he knows more about the scene and is in the position to inform Kapa about it, even if his own knowledge about it remains limited. The participants are not yet able to solve the problem or find a way forward and the search continues through moving the character to new locations. 


\section{Changing roles and epistemic positions: towards epistemic symmetry}

The next excerpt shows how the players' participation is beginning to change after several occasions of playing together. In this excerpt we find the players navigating a new scene, which takes place in a library in the palace. The playable character is moving around in this space searching for clues. Pete is still in control of the game, but Kapa's participation has slightly changed: he is now active in suggesting what to do next.

EXCERPT 3. FFIX: Find the right book.

$1 \quad$ (.) ((change of scene, game character in a library))

$2 \quad(0.5)((\mathrm{P}$ moves character up stairs $))$

$3 \rightarrow \mathrm{K}$ 个find the right boo:k

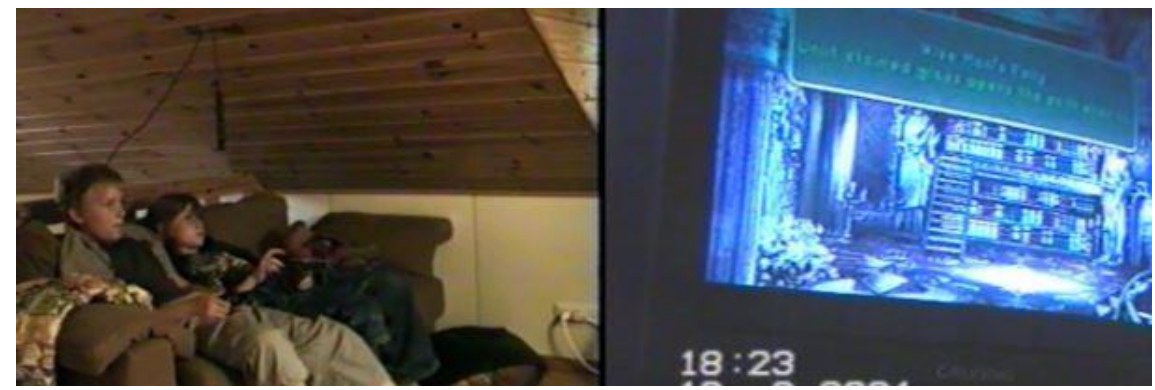

Fig. 3. Wise man's folly. Unlit stained glass opens the path when lit. 
$5 \rightarrow \mathrm{K}$ un::, unlit steined glääs oupen mitä(h)

un::, unlit stained glass open what(h)

$6 \quad(1.5)$

$7 \mathrm{~K}$ jooh,

yeah,

$8 \quad(1.0) \quad((\mathrm{P}$ moves the character who lights a lamp;

new stairs appear; character moves towards them))

$9 \rightarrow \mathrm{K}$ no niin portaat

okay stairs

$10 \quad(2.0)(($ character moves up a staircase, comes down again))

$11 \rightarrow \mathrm{K} \quad+$ sytytä ne toisetki lamput

+light the other lamps too

$+(($ character moves up the stairs $)) \quad(3.5)$ 
$12 \mathrm{P}$ (täällähän on ) ((whispering))

(here there is $\mathrm{xx}$ )

13 (1.5) ((character looks at the books))

$14 \mathrm{P} \quad[\mathrm{hm}]$

$15 \mathrm{~K} \rightarrow$ [ei ] niitä kirjoja voi tutkia=

you can't examine those books

$16 \mathrm{P}=\mathrm{hmh}$ täälä ei oo mitää:n

$=\mathrm{hmh}$ there's no:thing here

Lie of the Archon

The path will open when all lamps are lit

$17 \quad(0.3)$

$18 \mathrm{P} \quad$ kiva (.) ei on tuolla tulee- tuli

nice (.) no there is comes- light

$19 \quad(2.5)(($ character lights another lamp $))$ 
$21 \mathrm{~K} \quad \uparrow_{\text {no }} \downarrow_{\text {nii }}$

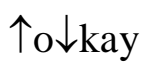

23 P tää kylä yhtää sekompi oo

this is not so mad as all that

The scene opens with the playable character entering the library with lots of books. Kapa promptly responds to the game situation with an English directive ('Find the right book', line 3) which can be interpreted as an instruction for Pete. This utterance is not visible on the screen; rather it seems to be occasioned by K's reading of the visual image and prior knowledge of the game. Pete does not respond verbally but continues moving the character around. Immediately after the verbal directive, the first clue appears on the screen (Fig. 3) and Kapa reads it aloud (line 5). While reading, Kapa displays trouble through self-repair and features of pronunciation: he pronounces the English words more or less according to the Finnish phonological system, adopting only some vowels from the original language (e.g. the first vowel in stained, the vowel in glass). His utterance ends with a repair initiator: the question word 'mitä' (what), pronounced with a hint of 
laughter. With the reading Kapa shows that he is closely monitoring the screen for clues, but displays limited ability to understand the linguistically complex and somewhat opaque clues. While showing recognition of some words, the reading aloud of the written clue does not indicate whether he understands any part of it. The source of the trouble is thus not specified. Nonetheless the display of trouble re-invokes the epistemic asymmetry between the participants and yields epistemic primacy to Pete, who is in charge of the controller. Pete, however, does not respond. The participants maintain asymmetrical positions with regard to the organization of action: while Pete continues to engage in play, Kapa's participation is restricted to verbal utterances, such as dialogue particles with which he accepts Pete's moves (e.g. 'yeah', line 7).

Earlier in the game the players negotiated a scene where a solution was found after lighting several lamps in a certain order (see Example 2). Pete seems to apply knowledge from this and other similar scenes to the current problem by moving the character close to a lamp in order to light it (line 8). Pete's strategy succeeds, and simultaneously to the lighting of the lamp new stairs appear. Kapa acknowledges this success (line 9). When Pete immediately starts to explore the new possibilities that open up (line 10), Kapa takes a more active role and proposes a next action: lighting the other lamps (line 11). While grounded in the knowledge based on ongoing monitoring of Pete's actions, his proposal also displays independent knowledge gained through participating in other similar situations. Pete, however, continues to search for clues in the books (lines 12-14). Kapa responds to this by offering his view which disagrees with Pete's chosen strategy (line 15), thereby again showing independent access to knowledge. Kapa's advice turns out to be accurate: the books do not offer any clues which Pete acknowledges in the following 
turn (line 16). After some further searching Pete finds another lamp, and when the character lights it, the book wall opens, which enables the player to enter another location and a new scene. Both boys seem to be content with their success (lines 21 and 23). Together they have managed to solve the problem.

The first three examples recorded when the players were aged 11 show that the participants orient to epistemic asymmetry and build a congruent relationship where Pete is established as the party entitled to know more about the game, its imaginary world, characters, game play options, commands, etc. than Kapa. They attend to this asymmetry in their interaction both in their verbal and nonverbal activities. In the first Excerpts (Excerpts 1 and 2), Kapa positions himself as a novice by asking questions and initiating repair. Pete often responds to Kapa's enquiries, unless he is involved in intensive gameplay. Pete thus acts cooperatively by providing aligning responses. In these situations the player's positions indicate a situation of epistemic congruence: they agree on both Pete's better access and greater authority over knowledge related to the game. The congruent positions are tied to the participants' social roles, interactional history and the specifics of the situation. Pete as the owner of the game has more experience of playing and is the one in control of the game in most of these early interactions, while Kapa's participation is restricted to following and monitoring his choices and participating in verbal negotiations through which various local tasks and problems are negotiated. However, he recurrently draws on local interactional resources to make most of the information available and to negotiate a local interactional role which allows him to display epistemic access. He reads aloud clues that appear on the screen, showing that he understands their significance in specific situations, and actively seeks clarification or 
new information by asking questions. With these activities he displays an orientation to learning about those features of the game that are relevant for solving the local problem or task. In the recordings that were made towards the end of the two-week period, we observe how Kapa makes increasing interactional efforts to negotiate a more symmetrical relationship by displaying independent access to knowledge of some aspect of the unfolding situation (Excerpt 3). The key sources of knowledge in such situations are the participants' joint history in navigating other similar game situations and the continued, joint visual monitoring of the scene under way. The excerpts demonstrate that in social gaming both shared history and simultaneous access to the game provide important sources of knowledge and also contribute to altering epistemic positions in the course of interactional episodes. Shared visual access to the object of knowledge (a game task or situation) enables also the novice player to display knowledge and challenge the epistemic primacy of the expert player. Finally, the examples show some evidence for changing epistemic positions that result from repeated occasions of play. In Excerpt 3 Kapa's participation in solving the problems shows orientation to prior knowledge and becomes more active: he begins to offer suggestions and advice which are more straightforwardly grounded in his developing independent knowledge of the game.

\section{Shared participation and control actions}

In the sessions of playing Final Fantasy IX and in the earliest sessions of playing Final Fantasy $\mathrm{X}$ the active player controlling the game is Pete, the owner of the games. As noted above, this is one of the contextual factors shaping the epistemic organization of 
these situations. In the later recordings of play sessions with Final Fantasy X the boys adopt a more symmetrical pattern of participation where they take turns in using the control. The following examples (Excerpts 4 and 5) are drawn from occasions where it is Kapa's turn to control the game and make the choices required in gameplay. Compared with the previous examples, the participants' roles are thus reversed. Pete is now the partner who follows Kapa's actions and participates in decision-making verbally and through vocal and non-vocal responses. The analysis highlights how epistemic positions are managed when Kapa is using the controller to take action, while attending to frequent instructions and other types of interventions from Pete. The examples come from battle scenes in which the player makes fast choices related to playable characters and special features of the game (e.g. items, potions, spells) in order to beat the enemy.

The next Excerpt begins with Kapa leading three characters, Tidus, Wakka and Yuna in a battle. Just prior to this event, he has succeeded in gaining points using a special spell (Watera), which Pete has complimented. In the course of the battle Kapa decides to change two of the characters involved in the fight. The players' interaction centers around the choice of an item to be used in the battle and the choice of one of the characters. The Excerpt is presented in two parts to highlight how the players manage their relative positions to different kinds of knowledge relevant to the task.

We enter the scene Kapa is changing one of the characters involved in the fight, opting for Rikku to replace Yuna (Excerpt 4a). When taking this action he makes his choices recognisable also to Pete by concurrently commenting on them verbally (lines 1 2). When he continues the attack, Pete intervenes to suggest using Fish Scale, an item that can be used to inflict water elemental damage in a fight (line 3). The relevant item is not 
shown on the screen, but has appeared earlier when Kapa was browsing the Use menu in preparation for the fight.

\section{EXCERPT 4a}

1 Kapa +nää kaikki voi nyt vaihtaa pois $+<$ Rikku $>$

all these can be changed now

$+(($ moving cursor on character menu, chooses Rikku $))$

joka ottaa tolta vesimölliltä jotain [hauskaa]

who is going to take something fun from that water creature

$3 \quad$ Pete

$4 \quad$ Kapa

5 Kapa +väärä paikka

+ wrong place

$+(($ chooses item and special $))$
$[$ Fish::: $]+>$ fish $<$ skale

$+(($ chooses potion $))$

6 Pete Fish kale $(0.3)+$ Fish:: kale

7 Kapa $+(($ chooses Steal $))$

Figure X Stole Fish Scale x 2 
8 Pete $\quad>$ kato ny< (.) Fish kale

$>$ look $<$

9 Kapa yeb $\uparrow$ yeb $\uparrow$ yeb

Kapa shows his expertise on the game situation (lines 1-2). However, he seems to immediately follow Pete's s suggestion to try 'Fish Scale': he chooses 'option', 'item' and 'special' in quick succession (lines 4 - 5). However, at the same time he verbally expresses doubt ("wrong place", line 5). Kapa's actions display that he has no trouble recognising Pete's suggestions or identifying the action suggested. He also shows independent knowledge in assessing whether this option is possible at this point. However, Pete reaffirms his claim to epistemic authority and continues to guide him by repeating the name of the item twice (line 6). The second repetition occurs concurrently with Kapa's complying action (choosing 'Steal') and is stretched to match the movement of the cursor on the screen. The action is successful, as indicated by the text appearing on the screen (see Fig. X). Pete's response (line 8) draws attention to this and treats the text as confirmation of his own expertise in guiding Kapa's choice. Kapa's playful response (line 9) both accepts Pete's position and celebrates the successful game move.

After this, Kapa decides to change another character involved in the fight. Excerpt $4 \mathrm{~b}$ shows how his online commentary enables Pete to get involved and influence his choice. 
EXCERPT $4 b$

10 Kapa Tiittus + vaiheta::an na:::na:::na::[na::na]

gonna change Tidus

$+(($ scrolls list of characters, stops at Kimahri $))$

11 Pete

[ÖÖRön] (Auron)

12 Kapa +U:rn (Auron) (hh)

+ chooses Auron

13 Pete se lyö keskimm[äischtä]

he's gonna hit the one in the middle

14 a [as you] wish=

15 Pete =tai jotain $=$

or something

16 Kapa =as you wish (.) pech

17 
18 Kapa dat's how it's $\downarrow$ done

19 Pete ei sano siin- (.) lopussa [sanotaan]

he doesn't say the- (.) in the end [it is said]

In line 10 Kapa verbally comments on his action while using the controller: he announces his decision to change Tidus and simultaneously scrolls on the character menu. Towards the end of the turn, he stops scrolling, suggesting that he is about to select the character Kimahri to replace Tidus. Pete, however, is quick to offer an alternative suggestion. With a playfully exaggerated pronunciation modified to Finnish phonology, he suggests Auron instead (line 11). The suggestion is immediately accepted by Kapa, who moves down on the menu and selects Auron, and also simultaneously responds to Pete in a playful mode (line 12). In lines 13-18 both participants comment on the scene. Pete anticipates Auron's fighting action (13 and 15) and Kapa imitates Auron's speech and the sounds of hitting (line 16) while he is dealing the blows in the game. In line 18 Kapa anticipates a verbal utterance by the character Auron and thus makes an epistemic claim . However, the utterance is out of place here, as the character does not speak. Pete comments on Kapa's try and displays detailed knowledge of the game in his response (line 19).

Excerpts $4 \mathrm{a}$ and $4 \mathrm{~b}$ illustrate how epistemic positions are managed in situations where Kapa is the party with access to the controller. Now Kapa's verbal contributions are tied to his own game play moves and display independent access to knowledge required in play and game's language. Kapa's verbal commentary shows that he is able to make decisions on the basis of close monitoring of the situation and draw on prior 
knowledge to assess his options. However, while managing the game, he also closely attends to Pete's frequent interventions and follows his suggestions even when in doubt about their applicability. Pete actively asserts his epistemic status by recurrently intervening in the actions and offering instructions and suggestions for next actions. The timing of Pete's utterances shows that he draws on his shared access to the visual information as well as his prior knowledge of the game, which enables him to guide Kapa's choices. Often Kapa complies with these, enabling Pete to maintain his position as the expert.

The last excerpt comes from a similar situation where Kapa is in charge of the game, prepares for a battle by choosing equipment and special abilities for the characters, and then operates them in the battle scene. He has used other characters prior to this moment, and here Pete suggests using Lulu. Kapa accepts this suggestion (line 3) and begins to make choices, voicing them aloud (lines 3-4).

EXCERPT 5. FFX: Glorious Bangle

((menu shows Glorious Bangle))

$1 \mathrm{~K} \quad$ Kenen on bangle

whose is bangle

2 P: Lul:un.

Lul:u's 
$3 \quad \mathrm{~K} \quad \uparrow+$ eguip. +Lulululululu:::

$+(($ selects equip, then + selects Lulu $))$

4 K: +Seeker's Bangle ja (tää) +\#Glo:rious\#

and (this)

$+(($ selects seeker's bangle and +glorious bangle $))$

$5 \mathrm{~K} \quad$ (.) Defense viis ja tossa on kaikkee [(muuta)]

Defense five and there is all the [(other stuff)

$6 \quad \mathrm{P}$

[paljon] See +ker's oli

[how much] was Seeker's

$+((\mathrm{K}$ begins to scroll $)$

$7 \quad \mathrm{~K} \quad(($ scrolls the menu to Seeker's bangle; display shows HP + 5))

$8 \quad \mathrm{~K} \quad$ HP [plus viis]

[plus five] ((starts to scroll down on menu -- >

$9 \quad \mathrm{P} \quad[\mathrm{E}:: \mathrm{I}$ pistä $+()+$. Glorious Bangle

$[\mathrm{N}: \mathrm{O}$ take

---- > +stops at Glorious Bangle+)) 
$11 \mathrm{P}$ katotaan mitä siihen vois lisätä

let's see what we could add

12

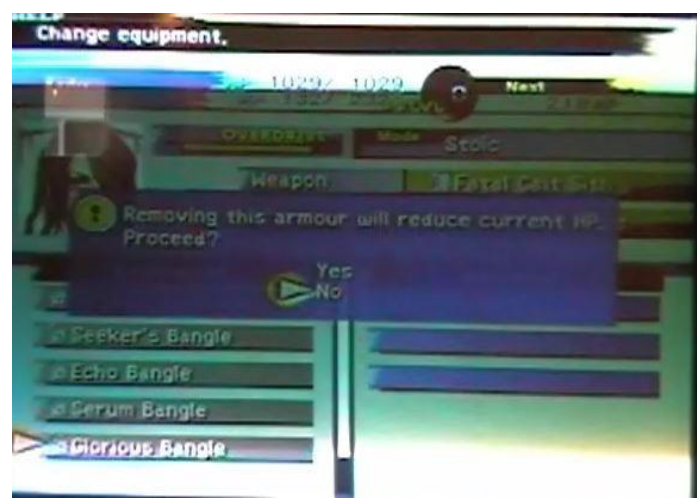

Fig. 8. Removing this armour will recure current HP. Reduce?

$13 \mathrm{~K}$ re[duse]

re[duce ]

$14 \quad \mathrm{P} \quad$ [joo joo]

[yea yea]

$15 \mathrm{~K}+(.) \mathrm{n}(\mathrm{h})$ oo ky[:1lä] 


$$
\begin{aligned}
& +(.) \text { o(h)kay y[e:s] } \\
& + \text { K selects 'yes'. }
\end{aligned}
$$

$16 \mathrm{P}$

[tulee] alle + tonni

[that'll be] under + a thousand

$$
((+ \text { gaze at } \mathrm{K}))
$$

$17 \quad \mathrm{~K}+\mathrm{e}[\mathrm{i}$ se oo niin, ]

[ it's not so,]

$((+$ nods $))$

$18 \quad \mathrm{P} \quad$ [ei sillä oo] mitään väliä

[ it doesn't] matter at all

\section{K Customise}

In this Excerpt Kapa's prompt acceptance of Pete's suggestion (lines 2 and 3) by immediately carrying out relevant choices and voicing them in his talk (lines 3 and 4) display independent access to the type of knowledge required to prepare the character for battle. At the same time his voiced online commentary makes his choices public and available for negotiation. In line 5 Kapa's voicing of a game term (Defense) responds to textual information on the screen. The turn occasions a question from Pete concerning the amount of 'defense' assigned to another choice in the equipment menu (line 6). Partly in 
overlap with his question, Kapa begins to scroll the menu to find the option that Pete refers to, and when the information is visible, he reads it aloud (line 8). While the information is locally available for both participants, Kapa thus orients to his role as the player in charge and displays epistemic primacy by finding the information and providing it. In overlap with his turn, Pete quickly proposes choosing another element ("Glorious Bangle", line 9) and suggests that it might be possible to increase the amount of 'defense' assigned to this equipment (line 11). Kapa, however, is simultaneously already scrolling the menu down and stops at the suggested item at the same time as Pete refers to it in his talk. In fact, the players synchronise their actions so closely in lines 8 and 9 that the decision to opt for the chosen element appears to be reached simultaneously. At this point a text appears on the screen which requires a response: Kapa needs to choose whether to remove this equipment and accept a reduction in the hit points (HP). Kapa reads aloud the key word in the text (line 13), thereby taking a moment to consider the decision. In overlap with his turn, Pete offers his own response to the choice (line 14), which Kapa accepts by choosing 'yes' with the control and confirming the choice also verbally (line 15). In line 16 Pete comments on the consequences of the choice, which involve less points than might be desirable, but both players agree to accept the decision in spite of this (lines 17 and 18). and the activity continues (line 19).

Excerpts 4 and 5 show how Kapa's epistemic position has changed in comparison to the earlier game sessions and how this change is manifested in his ability to rely on independent knowledge when controlling the game. His verbal utterances are no longer typically oriented to visual trouble sources or problems in following and understanding the textual clues. Rather, they display ability to recognise and respond to visual cues in a 
timely and competent manner. Kapa's commentary while engaged in play is closely tied to the timed organisation of his own actions and displays independent access to knowledge that is relevant to the choices he makes. Kapa also closely attends to the coparticipant's verbal instructions and suggestions, and often adjusts his actions accordingly. His growing game know-how is displayed in particular in situations where his actions in control of the game are closely synchronised with the verbal participation of the co-participant, as in Excerpt 5. Kapa's expertise is manifested in the speed with which he responds to Pete's enquiries. Sometimes the game-play actions are so closely synchronized with the verbal interventions that it is impossible to see whether Kapa's choices are in any way influenced by Pete or whether they are the result of joint or independent reasoning.

\section{Conclusion}

This paper has investigated how changing positions on knowledge constitute a bilingual video gaming activity as a learning event and have consequences on the social organization of the event. Through detailed analysis of temporally spread social gaming interactions involving the same two participants, we have aimed to demonstrate how the participants orient to and manage knowledge asymmetries in the context of local game situations, and document how their epistemic positions change over time. The analysis details how knowledge and epistemic asymmetries are managed through social interaction in a gaming event and how changes in the epistemic organization of the encounters are informative of the process of learning the know-how of games. The 
findings add to emerging research on the epistemic organization of multilingual and second language interactions (see e.g. Koole, 2012a, 2012b). They also contribute to a better understanding of the kinds of resources that games as multimodal and multilingual activity settings afford for social interaction (see e.g. Thorne, 2008). More specifically, the findings highlight the kinds of interactional competence displayed in gaming interaction and sheds new light on the way that such competencies evolve moment-bymoment and changen over time (Hall, Hellermann \& Pekarek Doehler 2011; Ngyen, 2012) .

The gaming interactions in focus are multilingual. The language of the game (English) is a second language to the players. The game also makes available other, heterogeneous linguistic resources, which enders use of multililingual and mixed language resources in talk. The ability to navigate the game, solve problems and manage game tasks relies on knowledge about the games as well as competences involved in reading on-screen texts and visual images, interpreting sounds (e.g. dialogue), and drawing inferences on the basis of which to carry out material actions (using the controller) that translate to gameplay moves. Social gaming situations that involve copresent participants also create opportunities for joint action, negotiation and decisionmaking (see e.g. author 1 \& author 2, 2009; author 1, 2011; Mondada 2012), making relevant additional interactional competences that the participants put to use in navigating game tasks. The analysis shows that the players' competences and roles differ, especially in the early encounters: in the first recordings the less experienced player frequently displays trouble for instance by reading aloud texts displayed on the screen, asking 
questions and initiating repair, whereas the more experienced player displays epistemic primacy e.g. through providing aligning responses which display epistemic access to relevant information (Excerpts 1-3). This pattern is constitutive of a congruent epistemic relationship between an expert and novice player. However, the participants also draw on available resources to manage and alter their epistemic positions. The semiotically rich multilingual setting affords specific resources for this. For example, reading aloud English texts on the screen can be used to initiate repair, but also to signal recognition of the importance of salient clues and appreciation of successful gaming moves. Both participants draw on the multimodal resources and the two co-available languages in coordinating their action and attention to the game. They incorporate linguistic resources of the game in their turns to display recognition of salient elements in the dynamics of the game and occasionally display both epistemic and affective stance through playfully recycling or translating game terms into their first language.

The analysis shows that participants draw on multiple sources of knowledge and a range of interactional resources when negotiating game tasks or situations and solving emerging problems. The key sources of knowledge are the participants' prior (joint) experience in navigating similar game situations and the continued, joint visual monitoring of the scene under way. Shared history with gaming and shared visual access to the game as 'object of knowledge' enable displays of knowledge by both the expert and the novice participant and afford resources for altering epistemic positions in the course of interactional episodes. This is visible in all the interactions in the way that the party who is not actively playing - initially the less experienced participant, later both - 
makes interactional efforts to negotiate a more symmetrical relationship by displaying independent access to knowledge of some aspect of the unfolding situation.

Comparison of interactional episodes from temporally spread gaming sessions shows that through repeated occasions of play, the less experienced participant's position gradually becomes more active: he begins to display independent access to knowledge and offer suggestions and instructions which are grounded in his developing know-how of the game and game's language (Excerpt 3). When his expertise deepens after gaining more experience, Kapa's contributions become more straightforwardly based on the actual possibilities of the game. His know-how is particularly visible in the speed with which he uses the controller to make game-play moves in the later recordings and the way that his actions are synchronized with the verbal instructions and comments of his more experienced partner (Excerpts 4 and 5). While actively involved in negotiating the game and continually displaying independent epistemic access to the tasks and situations that unfold, Pete is no longer the party with full epistemic primacy to matters related to the game. Kapa's independent access and epistemic stance is visible in his verbal conduct, which is no longer restricted to reading or repair initiations, but includes utterances that display independent reasoning, index the actions he carries out in the game, and comment on the in-game actions and scenes from the position of epistemic primacy. In sum, comparison of data from the two sets of recordings shows how the initially less knowledgeable participant (Kapa) has acquired resources for showing independent access to knowledge of the game and its language which display growing expertise. This change in the epistemic organization contributes to more equal opportunities to participate and a 
cooperative stance. The data also show an increase in interactional synchrony over time, which suggests that the participants have developed a shared and mutually known rhythmic pattern which enables closely coordinated collaborative action (cf. Nguyen, 2012). The data suggest that epistemic changes as displayed in the participants' interactional positionings to knowledge and their orientations to the distribution of knowledge are constitutive of trajectories of learning to 'read' a game and solve gamerelated problems through social game-playing in a multilingual context.

\section{References}

Aarsand, P., \& Aronsson, K. (2009). Response cries and other gaming moves - Building intersubjectivity in gaming. Journal of Pragmatics, 41, 1557-1575.

Arminen, I. (2005). Institutional interaction. Studies of talk at work. Aldershot, Hants: Ashgate.

Bialystok, E. (2006). Effect of Bilingualism and Computer Video Game Experience On the Simon Task. Canadian Journal of Experimental Psychology, 60, 68-79.

Brouwer, C., \& Wagner, W. (2004). Developmental issues in second language conversation. Journal of Applied Linguistics, 1, 29-47.

Cekaite, A. (2007). A child's development of interactional competence in a Swedish L2 classroom. The Modern Language Journal, 91, 45-62. 
Cekaite, A. (2009). Collaborative corrections with spelling control: digital resources and peer assistance. Computer-Supported Collaborative Learning, 4, 319-341.

Carroll, D. (2006). Co-constructing competence: turn construction and repair in noviceto-novice second language interaction. Unpublished PhD Dissertation, University of York, UK, Communication Studies Program.

Cornilie, F., Thorne, S., \& Desmet, P. (2012). Digital games for language learning: from hype to insight? ReCALL, 24, 243-256.Drew, P. (1991). Asymmetries of knowledge in conversational interactions. In Marková, , \& K. Foppa (Eds.), Asymmetries in Dialogue (pp. 21-48). Hemel Hempstead, UK: Harvester Wheatsheaf.

Ducheneaut, N., Yee, N., Moore, R. J., \& Nickel, E. (2006). “Alone Together?" Exploring the Social Dynamics of Massively Multiplayer Online Games. In $C H I$ 2006 Proceedings (pp. 407-416). New York: ATM Press.

Gee, J. P. (2003).

Gee, J. P. (2007). Good video games and good learning. New York: Peter Lang.

Goodwin, C. (2000). Action and embodiment within situated human interaction. Journal of Pragmatics, 32, 1489-1522.

Goodwin, C. (2007). Participation, stance and affect in the organisation of activities. Discourse and Society, 18, 53-73.

Goodwin, C., \& Goodwin, M. H. (2012). Car talk: Integrating texts, bodies, and changing landscapes. Semiotica, 191, $257-286$. 
Green, C., \& Bavelier, D. (2003). Action video game modifies visual selective attention. Nature, 423, $534-537$.

Greiffenhagen, C., \& Watson, R. (2009). Visual repairables: analysing the work of repair in human-computer interaction. Visual Communication, 8, 65-90.

Hall, J. K., Hellermann, J., \& Pekarek Doehler, S. (Eds.). (2011). L2 Interactional competence and development. Bristol: Multilingual Matters.

Hall, J. K., \& Pekarek Doehler, S. (2011). L2 Interactional Competence and development. In J. K. Hall, J. Hellermann, \& S. Pekarek Doehler (Eds.), L2 Interactional Competence and Development (pp. 1-15). Bristol: Multilingual Matters.

Hellermann, J. (2008). Social actions for classroom language learning. Clevedon, UK. Multilingual Matters.

Hellermann, J. (2011). Members' methods, members' competencies: looking for evidence of language learning in longitudinal investigations of other-repair. In J. K. Hall, J. Hellermann, \& S. Pekarek Doehler (Eds.), L2 interactional competence and development (pp. 147-172). Bristol: Multilingual Matters.

Heritage, J. (2012a). Epistemics in action: action formation and territories of knowledge. Research on Language and Social Interaction, 45, 1-29.

Heritage, J. (2012b). The epistemic engine: sequence organization and territories of knowledge. Research on Language and Social Interaction, 45, 30-52.

Hung, A. C. Y. (2009). 
Hung, A. C. Y. (2011). The work of play. Meaning-making in video games. New York: Peter Lang.

Kasper, G. (2004).

Kasper, G., \& Wagner, J. (2011). A conversation analytic approach to second language interaction. In D. Atkinson (Ed.). Alternative approaches to second language acquisition (pp. 117 - 142). Oxford: Routledge.

Keating, E., \& Sunakawa, C. (2010). Participation cues: coordinating activity and collaboration in complex online gaming worlds. Language in Society, 39, 331-356.

Keating, E., \& Sunakawa, C. (2011). A Full Inspiration Tray: Multimodality across Real and Virtual Spaces. In G. Streeck, C. Goodwin, \& C. LeBaron (Eds.), Embodied interaction: Language and body in the material world (pp. 194-206). Cambridge: Cambridge University Press.

Koole, T. (2010). Displays of Epistemic Access: Student responses to teacher evaluations. Research on Language and Social Interaction, 43, 183-209.

Koole, T. (2012a). The epistemics of student problems: Explaining mathematics in a multi-lingual class. Journal of Pragmatics, 44, 1902-1916.

Koole, T. (2012b). Teacher evaluations: assessing 'knowing', 'understanding', and 'doing'. In G. Rasmussen, C. Brouwer, D. Day (Eds.), Evaluating Cognitive Competences in Interaction (pp. 43-66). Amsterdam: Benjamins.

Markee, N. (1994).

Markee, N. (2000). 
Markee, N. \& Seo, ?? (2009).

Melander, H., \& Sahlström, F. (2011). Non-verbal epistemic claims in educational settings. Paper presented at the 12th International Pragmatics Conference (Manchester, 3-8 July 2011).

Mondada, L. (2011). The management of knowledge discrepancies and of epistemic changes in institutional interactions. In T.Stivers, L. Mondada, \& J. Steensig, (Eds.), The morality of knowledge in conversation (pp. 27-57). Cambridge: Cambridge University Press.

Mondada, L. (2012). Coordinating action and talk-in-interaction in and out of video games. In R. Ayaß, \& C. Gerhardt (Eds.), The appropriation of media in everyday life (pp. 231-270). Amsterdam: Benjamins.

Mondada, L. (2013). Coordinating mobile action in real time: The timely organization of directives in video games. In P. Haddington, L. Mondada and M. Nevile (Eds.), Interaction and mobility: Language and the body in motion (pp. 300-344). Berlin: Walter de Gruyter.

Mondada, L., \& Pekarek Doehler, S. (2004). Second language acquisition as situated practice: task accomplishment in the French second language classroom. The Modern Language Journal, 88, 501-518.

Mori, J. (2004). 
Nguyen, H. (2011). Achieving recipient design longitudinally: evidence from a pharmacy intern in patient consultations. In J. K. Hall, J. Hellermann, \& S. Pekarek Doehler, (Eds.), L2 interactional competence and development (pp. 173-205). Bristol: Multilingual Matters.

Nguyen, H. (2012). Social interaction and competence development: Learning the structural organization of a communicative practice. Learning, Culture and Social Interaction, 1, 127-142.

Newon, L. (2011). Multimodal creativity and identities of expertise in the digital ecology of a world of warcraft guild. In C. Thurlow, \& K. Mroczek (Eds.), Digital Discourse: Language in the New Media (pp. 309-341). Oxford, UK: Oxford University Press.

Pallotti, I., \& Wagner, J. (2011).

[author $1 \&$ author 2]. (2009a). Prosodic repetition as a resource for participation in the activity of playing a video game. The Modern Language Journal, 93, 153-169.

[author $1 \&$ author 2]. (2009b). Collaborative game-play as a site for participation and situated learning of a second language. Scandinavian Journal of Educational Research, 53, 167-183.

[author 1]. (2010). Bilingual practices and the social organisation of video gaming activities. Journal of Pragmatics, 42, 3012-3030.

[author 1]. (2011). Enacting Interactional Competence in Gaming Activities: Coproducing Talk with Virtual Others. In J. K. Hall, J. Hellermann, \& S. Pekarek 
Doehler (Eds.), L2 interactional competence and development (pp. 19-44). Bristol: Multilingual Matters.

[author 1] (2012). Intertwining actions in real and virtual worlds: discursive resources for organizing participation in video-gaming activities. In R. Ayass, \& C. Gerhardt, (Eds.), The Appropriation of Media in Everyday Life. What people do with Media (197-230). Amsterdam: Benjamins.

Sahlström, F. (2011). Learning as social action. In J. K. Hall, J. Hellermann, \& S. Pekarek Doehler, (Eds.), L2 interactional competence and development (pp. 45-65). Bristol: Multilingual Matters.

Salen, K. (Ed.). (2008) The ecology of games. Connecting games, youth and learning. Cambridge, MA: The MIT Press.

Schott, G., \& Kambouri, M. (2006). Social play and learning. In D. Carr, D. Buckingham, A. Burn, \& G. Schott (Eds.), Computer games: text, narrative and play (pp. 119-148). Cambridge: Polity Press.

Sjöblom, B. (2011). Gaming interaction: Conversations and competencies in internet cafés. Linköping Studies in Arts and Science No. 545. Lingköping: University of Linköping.

Steinkuehler, C. (2006). Massively multiplayer online videogaming as participation in a discourse. Mind, Culture, \& Activity, 13, 38-52. 
Steinkuehler, C. (2008). Cognition and literacy in massively multiplayer online games. In J. Coiro, M. Knobel, C. Lankshear, \& D. Leu, (Eds.), Handbook of research on new literacies (pp. 611-634). Mahwah, NJ: Erlbaum.

Stivers, T., Mondada, L., \& Steensig, J. (2011). The morality of knowledge in conversation. Cambridge: Cambridge University Press.

Thorne, S. (2008). Transcultural communication in open internet environments and Massively Multiplayer Online Games. In S. S. Magnan (Ed.), Mediating Discourse Online (pp. 305-327). Amsterdam: John Benjamins.

Thorne, S. (2010). The 'intercultural turn' and language learning in the crucible of new media. In F. Helm, \& S. Guth (Eds.), Telecollaboration 2.0 for Language and Intercultural Learning (pp. 139-164). Bern: Peter Lang.

Thorne, S.L., Black, R. W., \& Sykes, J. (2009). Second language use, socialization, and learning in Internet interest communities and online gaming. The Modern Language Journal, 93, 802-921.

\author{
APPENDIX \\ Transcription conventions \\ word Stress or emphasis \\ Falling intonation \\ Level or slightly rising intonation
}




\begin{tabular}{|c|c|}
\hline$?$ & Rising intonation \\
\hline- & Cut-off \\
\hline$\uparrow$ & Change in pitch height: higher than preceding speech \\
\hline$\downarrow$ & Change in pitch height: lower than preceding speech \\
\hline$><$ & Faster tempo \\
\hline$<>$ & Slower tempo \\
\hline : & Sound stretch \\
\hline really & Stressed syllable \\
\hline CAPITALS & Loud voice \\
\hline$\circ \circ$ & Quiet voice \\
\hline \# & Creaky voice \\
\hline$()$. & Pause, less than $0.3 \mathrm{~s}$. \\
\hline$(0.5)$ & Length of pause \\
\hline$(())$ & Transcriber's description of nonverbal activity or on-screen event \\
\hline hh .hh & Out-breath/in-breath \\
\hline $\mathrm{j}(\mathrm{h}) \mathrm{oo}$ & Laughing production \\
\hline$[\quad]$ & Overlap \\
\hline$=$ & Latching of turns \\
\hline$+\quad+$ & Timing of nonverbal activity in relation to talk \\
\hline
\end{tabular}


i Text boxes are used for reasons of space and clarity in cases when it has not been possible to provide an image of high enough quality. 